\title{
Inter-firm collaboration and innovation performance for new-to-market products: the moderating role of technological and skills-related knowledge assets
}

\begin{abstract}
This study examines the impact that the two types of knowledge assets - technological knowledge and skills-related knowledge - have on the link between inter-firm collaboration (IFC) and product innovation performance, measured by the sales share of new-to-market products. Drawing on Transaction Cost Economics, we propose that the relation specificity of these knowledge assets that a firm shares with its partners (reflecting its level of R\&D and training investments respectively) is a key determinant of the benefits and transaction costs associated with IFC. Using a two-wave panel of 480 innovating firms in the Australian state of Tasmania, we find that the observed positive association between IFC and the sales share of new-to-market products declines at high levels of R\&D and training intensities. Our findings help strengthen an understanding of the role of transaction costs for relation-specific knowledge assets and the factors that could influence the value of IFC as a pathway to enhanced innovation performance for new-to-market products.
\end{abstract}

Keywords: Inter-firm collaboration (IFC); innovation performance; new-to-market products; technological knowledge; skills-related knowledge; Transaction Cost Economics.

\section{Introduction}

The question of how collaboration influences a firm's ability to innovate and appropriate the benefits of innovation lies at the heart of innovation research. In this study, innovation refers 
to 'technological ${ }^{1}$ product innovation' (OECD/Eurostat, 1997, p.9) or "the implementation [and] commercialisation of a product with improved performance characteristics such as to deliver objectively new or improved services to the consumer". The increased attention given to collaboration is partly due to a shift in economic theories of innovation from a linear model towards a non-linear, dynamic and interactive model that recognises the importance of both explicit $^{2}$ and tacit ${ }^{3}$ knowledge in innovation and technology transfer (Mention, 2011; von Hippel, 1988). Within this model, innovation, instead of occurring in isolation, commonly requires interaction with other firms and the use of knowledge acquired from sources external to the firm.

In general, the innovation literature portrays collaboration involving knowledge transfer as taking one of two basic forms: 'inter-firm collaboration' (IFC) within supply-chain networks or between competing firms (von Hippel, 1988), and 'non-inter-firm collaboration' between firms and public research organisations e.g. universities or public research institutes (Mansfield \& Lee, 1996). IFC for the purpose of innovation involves voluntary participation by collaborating (and sometimes competing) firms in a managed and controlled exchange process where the primary currency of exchange is knowledge that leads to innovation; this is different to non-inter-firm collaboration which generally focuses on non-competitive learning of a technology or other types of know-how held by the collaborating partner/s (Cassiman \& Veugelers, 2002). A major focus of management in IFC is meeting the challenge of ensuring the knowledge required for innovation is transferred between partner firms with positive effect on the collaborative goals ${ }^{4}$. This focus is heightened in IFC for the implementation and

\footnotetext{
${ }^{1}$ The term 'technological' does not necessarily involve the use of high-technology plant and equipment (OECD/Eurostat, 2005).

${ }^{2}$ Explicit knowledge refers to knowledge that is codified, formalised, written down or taught (Nonaka, 1994).

${ }^{3}$ Tacit knowledge refers to rich experience-based knowledge which is difficult to define, communicate or formalised (Nonaka, 1994).

${ }^{4}$ Collaborative goals include, for example, the successful joint development and/or commercialisation of new products by firms that possess complementary knowledge assets.
} 
commercialisation of new-to-market (novel) innovations, which presents greater challenges in relation to the management of knowledge transfer between partners than IFC directed towards new-to-firm (incremental) innovations (Oxley \& Sampson, 2004).

As knowledge is the basis for innovation, it thus becomes prerequisite for engagement in IFC; in other words, a firm must be able to contribute knowledge which is specifically required for the particular innovation for which collaboration is required, and which its collaborating partners currently lack and are not independently able to create cost-effectively. The necessary and specialised nature of the knowledge that each collaborating firm is able to contribute creates dependence between the collaborating firms, which shapes the structural arrangements partner firms agree to put in place for managing collaboration and knowledge transfer (Dyer, 1997). Whether or not a collaborating firm can realise a positive return on its involvement in IFC for innovation is dependent not only on the firm's investment in its own knowledge assets, but also on its capacity to economise on the cost of establishing a proper system for protecting its commercial interests generally, and specifically in regard to the knowledge assets it transfers to partner firms (Dyer, 1997).

Many studies have investigated the link between IFC and innovation performance, with results demonstrating a positive effect for enhanced learning capabilities, improved production efficiencies, lower innovation-development costs and lower market uncertainty, each of which have been shown to enhance a firm's innovation performance (Ahuja, 2000; Harding, 2001; Powell, Koput \& Smith-Doerr, 1996; Zeng, Xie \& Tam, 2010). Yet, there is an important gap in this research; namely, the insufficient attention given to factors related to transferring specific types of knowledge assets that can negatively moderate the relationship between IFC and innovation performance (Pisano, 1990; Williamson, 2002; Wu, 2012). Empirical studies have failed to consider, at least conceptually, things such as: the transaction costs related to structural arrangements for managing knowledge transfer and controlling the negative 
consequences of unwanted leakage of knowledge to partners, opportunism and the role of bounded rationality; all of which have been theorised as possible influences on the relationship (Doz, 1996; Mora-Valentin, Montoro-Sanchez \& Guerras-Martin, 2004).

This paper addresses this gap in the empirical literature by testing the impact that the two types of knowledge assets - technological knowledge and skills-related knowledge - held by collaborating firms have on the link between IFC and innovation performance for new-tomarket products. We draw on Transaction Cost Economics (Williamson, 1985) to frame our research proposition and the hypotheses to be tested, which appear in the following section.

\section{Theoretical background and hypotheses}

For this study we draw on three particular basic tenets of Transaction Cost Economics (TCE): firstly, that transactions are the basic units of interaction between transactors; secondly, that the assets which are transacted will be specific to the purpose of the relationship between the transactors; and thirdly, that the extent to which the transacted assets are relation-specific gives rise to the risk that transactors can behave opportunistically in pursuit of 'self-interest with guile' (Williamson, 1985). In line with these tenets and the innovation literature, we consider IFC for innovation to be voluntary arrangements by which the collaborating firms (transactors) engage in a relationship that can lead to the development and commercialisation of new-tomarket products, involving the exchange (transactions) of previously exclusive knowledge assets specific to the relationship's purpose, and which is too expensive for partner firms to produce independently, and/or not easily accessed or acquired through market exchange (Ahuja, 2000; Teece, 1992). During such IFC, the exchange of relation-specific knowledge (assets) occurs most often via multiple exchanges over time between partner firms, rather than being a 'once-off' event; moreover, the series of transactions through which a firm's exclusive 
knowledge becomes shared knowledge creates a state of dependency between the collaborating firms (Williamson, 1985).

Under such conditions, opportunistic self-interested behaviour by partner firms may occur. In other words, the risk of a firm manipulating transactions with its collaborating partners, for the purpose of covertly expropriating what was previously exclusive knowledge of another partner firm, in order to further its own commercial interests and competitive advantage, is inherent in IFC (Agarwal \& Ramaswami, 1992; Williamson, 1985). According to TCE, decision-making by firms about how best to manage this risk, and limit partner firm behaviour to that which is in the shared interest of the IFC, is made problematic by the asymmetry in the amount of information available about each partner firm, uncertainty in the external environment, and by 'bounded rationality', a condition where firms neither have access to all relevant information nor fully comprehend all information that is available to them (Simon, 1991). Consequently, management of the so-called 'transaction costs', associated with safeguards e.g. exchange monitoring mechanisms, enforcement arrangements for ensuring performance compliance with the collaborative agreement, and investments in critical activities e.g. information gathering about, and building trust between partner firms, is a necessary component of IFC (Dyer, 1997).

Firms most commonly adopt (at least in Western economies) the risk management approach of relying on a legal contract for specifying, monitoring and enforcing formal collaborative arrangements (Dyer, 1997; Hamel, 1991). The suitability of relying solely on a formal approach for managing risk depends on several factors, not the least being the extent to which the knowledge is necessary for the specific innovation objectives of the IFC i.e. its 'relation specificity' (Nooteboom, 1993), and the nature of the knowledge itself (Shrader, 2001). TCE suggests relation specificity associates positively with transaction costs, which means the higher the level of relation specificity a firm's knowledge has in the case of IFC for 
innovation, the higher the costs will be for monitoring and enforcing arrangements and safeguards for protecting both the singular interests of the firm and the shared collaborative interests (Dyer, 1997). These transaction costs will also be affected by the form in which the firm's knowledge exists. For example, when the IFC involves the transfer of knowledge which is explicit and codified, formal contractual safeguards are likely to be effective and less costly. In contrast, when the knowledge to be exchanged is tacit and non-codified, a formal contractual-based risk management approach by itself will be inadequate, and other informal trust-based self-enforcing safeguards will be needed to complement the formal contractual arrangements, thereby increasing costs (Buckley \& Casson, 1996; Shrader, 2001).

How successful firms are in risk managing the transfer of their knowledge, and ensuring transactions contribute to the specific purpose of the IFC, will determine the extent to which each firm will benefit. Research suggests that benefits stemming from the exchange between partners of knowledge for innovation can include: cost and risk reduction in the innovation process (Das \& Teng, 2000); efficiency gains through economies of scale/scope (Ahuja, 2000); development of firm competencies (Mitchell \& Singh, 1996); enhancement of learning capability (Powell et al., 1996); improvement in capabilities for assimilation of technologies (Wu, 2012); access opportunities to new markets (Mowery, Oxley \& Silverman, 1998); and greater likelihood of innovation success (Ahuja, 2000). On the basis of such potential benefits, IFC presents as an attractive and logical option for firms to enhance their innovation capabilities and expand rapidly into new markets. However, if the costs and benefits of IFC are less favourable than that of committing the necessary assets to internalise knowledge transfers and pursue innovation in-house, logically firms should opt not to engage in IFC.

To determine whether IFC is indeed the best option for innovation, and given that the transfer of knowledge is at the heart of the costs and benefits of IFC, we suggest that broadening understanding of the impact that knowledge has on the link between IFC and innovation 
performance for new-to-market products is an important research aim. Thus, in line with TCE, we consider the following general proposition: that the relation specificity of two types of knowledge assets - technological and skills-related - is a key determinant of the benefits and transaction costs associated with IFC. In particular, where the contribution of IFC is on the development of new-to-market product innovations, the relation specificity of these exclusive knowledge assets that a firm shares with its partner firms, will reflect its level of research and development and innovation-related training investments respectively. The two specific hypotheses we derive for testing from the above proposition are outlined separately below.

\subsection{Technological knowledge and 'R\&D intensity'}

The role of research and development (R\&D) in the creation of technological knowledge has been identified as a key factor for innovation success. Scholars commonly use the level of R\&D investment or 'R\&D intensity' as a proxy for the specialised technological knowledge a firm gains from its R\&D activities (Garud \& Nayyar, 1994; Tsai \& Hsieh, 2009; Shrader, 2001). Research suggests that firms with high R\&D intensity are more likely to be able to: understand similarities and differences between the technological knowledge held by partner firms; identify what knowledge is critical to the purpose of IFC; and use that knowledge in technological innovation (Cohen \& Levinthal, 1990; Tsai \& Hsieh, 2009). The successful development of a novel innovation, as indicated by Laursen and Salter (2006), requires a considerable investment in $\mathrm{R} \& \mathrm{D}$ (compared to that required for the less complex incremental innovation) to create the necessary specialised technological knowledge.

However, technological knowledge is often tacit and poorly codified, complex and surrounded with uncertainty; thus, it is particularly subject to transfer risks and the associated higher transaction costs (Anderson \& Gatignon, 1986; Shrader, 2001). As suggested earlier, these knowledge characteristics constrain the ability to enact formal contractual agreements 
that fully safeguard intellectual property and require informal collaborative agreements to supplement the formal safeguards; as a consequence, the potential risks and costs associated with opportunism are increased (Shrader, 2001). Furthermore, tacit technological knowledge may even be, in some cases, too complex for a firm's personnel to know and understand fully, thereby making it difficult to communicate to partner firms in the IFCs (Buckley \& Casson, 1996). In such circumstances, firms also then face the problem of not being able to assess fully the tacit (or explicit) knowledge a partner firm wishes to contribute to the IFC, until that knowledge is disclosed and its relation-specific value agreed by the collaborating partners (Dyer, 1997).

On the basis of the above discussion, we argue that firms engaged in high R\&D intensity in order to create the prerequisite technological knowledge for IFC and innovation performance for new-to-market products, incur higher risks and transaction costs related to transferring and protecting technological knowledge. Although high R\&D intensity is likely to increase innovation success, its interaction with IFC may possibly result (due to increased transaction costs) in a dampening effect on firm innovation performance (Mowery, Oxley \& Silverman, 1998). Put simply, we surmise that the effect of R\&D intensity for technological knowledge on the IFC-innovation performance association may not always be positive. Therefore, we propose the following:

Hypothesis 1: The association between IFC and innovation performance for new-tomarket products is negatively moderated by $R \& D$ intensity.

\subsection{Skills-related knowledge and 'training intensity'}

Research suggests that the success of innovations is contingent upon investment in the necessary human capital skills to develop new products and enhance innovation performance (Ciriaci, 2011; Lundvall \& Nielsen, 2007; Piva \& Vivarelli, 2009; Svetlic \& Stavrou-Costea, 
2007). Both Ciriaci (2011) and Toner (2011) suggest using 'training intensity' as a proxy for the skills and knowledge gained from internal and external training activities, and which are necessary to develop and introduce innovations. Note that for the purposes of this study we use 'training' to mean skills acquisition for short-term (necessary for existing innovation projects) and for the long-term (strategic development of skills for possible future innovation projects). Such training when undertaken across the firm helps facilitate the sharing and application of tacit and explicit innovation-related knowledge between individuals (Nonaka, Toyama \& Nagata, 2000).

Research has demonstrated that intensive investment in skills-related training and development not only can positively affect a firm's own innovation performance, but can also result in skills-related knowledge that has high relation specificity for IFC. The investment by one firm in improving its level of innovation-related skills and knowledge can provide relationspecific knowledge which, when transferred and shared in IFC, not only enhances the collective innovation performance of the collaborating firms but also may have the post-IFC effect of boosting the innovation performance (and hence profits) of each firm (Ciriaci, 2011; Tether, Mina, Consoli \& Gagliardi, 2005; Stevens, 1996). However, there are direct costs incurred for the provision of the training itself, as well as indirect costs such as the higher wage demands that training, in conjunction with a shortage of suitably skilled people in the labour market, can generate (Prais, 1995).

As in the case of technological knowledge discussed earlier, the type of skills-related knowledge transferred during IFC for innovation has implications in terms of risks, costs and benefits for each firm. Becker (1964) developed a widely-used framework that classifies skills as one of two types: either 'general' (useful to many firms) or 'specific' (useful to a single firm). This distinction between general and firm-specific skills was further developed by Stevens (1996) as the basis for a third type called 'transferable' skills, i.e. those skills which 
can be specific to the investing firm but which, unlike 'general' skills of use to many firms, are of use to the investing firm plus at least one other firm or only a few firms. In the context of IFC for innovation, each of these three types of skills-related knowledge can form the basis for transactions between partner firms, but the extent to which each type of skills-related knowledge might be relation-specific and incur transaction costs will be different. We suggest that only 'transferable' skills-related knowledge is most likely to have high relation specificity and therefore higher transaction costs for IFC. Specific skills-related knowledge, the value of which is strictly firm-specific and therefore not seen by other firms as useful or necessary for IFC, has by definition no relation specificity and therefore no transaction costs. Similarly, the relation specificity and therefore transaction costs of 'general' skills-related knowledge are likely to be quite limited because its value in IFC for innovation is diluted by its generic nature.

For example, if a firm invests directly in innovation skills-related training specifically to extend its knowledge base and so enhance its own product innovation performance, but by doing so it creates an asset in the form of 'transferable skills' with high relation specificity for IFC, indirect costs associated with the transfer of that asset are likely to be high because of the need to control for opportunism and manipulation of transactions by firms with a lesser skillsknowledge base wishing to gain a competitive advantage. That such skills-related knowledge is vested in employees raises another possible risk associated with IFC for innovation; namely, that firms which have not incurred the same level of training investment in developing their skills-related knowledge (and possibly as a result are able to offer higher wages) may engage in opportunism and seek to 'poach' the trained employees or 'free-ride' on the investing firm (Tether et al., 2005). On the other hand, if partner firms are incapable of or not interested in taking advantage of the knowledge on offer, then indirect costs associated with the free-riding or poaching risks will be diminished. 
The risks of opportunistic poaching or free-riding are likely to be more acute in the case of IFC contributing to the development and commercialisation of new-to-market products, as they often require specific skills that will inevitably be in short supply, creating an incentive for poaching (Tether et al., 2005). Because IFC provides an opportunity for a firm to identify employees with valuable transferable skills-related knowledge in partner firms (Belderbos, Carree, Diederen, Lokshin \& Veugelers, 2004), specific safeguards are required to counter the risk of poaching or free-riding e.g. employee confidentiality agreements, retention and performance incentives (Ashton \& Green, 1996). On this basis, we argue that the transaction costs incurred to manage the risks of unwanted staff transfer are likely to be high, particularly when there is a high degree of competition between firms in novel product markets. Hence, while training intensity is likely to increase innovation success, its interaction with IFC (due to increased transaction costs) may possibly result in a negative effect on firm novel product innovation performance. In other words, we suggest the effect of training intensity for skillsrelated knowledge on the IFC-innovation performance association may not always be positive. Therefore, we propose the following:

Hypothesis 2: The association between IFC and innovation performance for new-tomarket products is negatively moderated by training intensity.

\section{Data and methods}

The data used in this study are drawn from the first and second Tasmanian Innovation Census (TIC), a survey of all firms with five or more employees in the Australian state of Tasmania. The TIC is based on the OECD/Eurostat's (2005) Oslo Manual's definitions and methods for measuring innovation activities. Most of the questions are similar to those in the European Community Innovation Survey. Each TIC asked about innovation activities during a three-year observation period and about innovation performance during the final, reference year of the 
observation period. The 2006 TIC covered innovation activities between January $1^{\text {st }} 2004$ and December $31^{\text {st }} 2006$ and obtained responses from 1,591 firms (56.7\% response rate), whilst the 2010 TIC covered a comparable three-year period from July $1^{\text {st }} 2007$ to June $30^{\text {th }} 2010$, with 1,401 responding firms $(61.8 \%$ response rate). Non-response analysis showed no significant differences between respondents and non-respondents in terms of their innovation status and a range of innovation activities.

In this paper, we restricted the analysis to only 480 'innovating' firms, i.e. those that reported any technological innovations in the two waves of the survey ${ }^{5}$. The TIC used several procedural remedies recommended by Podsakoff, MacKenzie \& Podsakoff (2003) to reduce common bias, such as proximal separation of measurement, the use of different scale formats, extensive explanatory texts for key constructs, and protection of respondent anonymity.

\subsection{Variables}

The dependent variable is innovation performance for new-to-market products, measured by the share of total sales in the reference year from new-to-market products introduced at any time during the three-year observation period. This dependent variable is a percentage measure that by definition is conditioned on values between $0 \%$ and $100 \%$. It is both left- and rightcensored; thus, Tobit regression is considered appropriate to model the data.

The independent variable is IFC, measured through questions on collaboration with four types of partners - suppliers, customers, consultants, and competitors or other businesses in the industry - to develop technological innovations. Each of these partners was firstly coded as 1 when the partner was reported and 0 otherwise. The IFC variable is constructed as the sum of the 4 partner types, with the values ranging from 0 to 4 . A high score is considered indicative

\footnotetext{
${ }^{5}$ This is because the questions on collaboration, $\mathrm{R} \& \mathrm{D} /$ training investments and innovation performance were only asked of firms that reported one or more technological innovations.
} 
of a high degree of IFC. By constructing the IFC variable in this way, the intensity of IFC can be captured and the possible bias caused by partnering with competing firms can be minimised $^{6}$. Nearly half (44\%) of respondents from innovating firms reported engagement in IFC, with $5.2 \%$ citing one, $14.2 \%$ citing two, $14.6 \%$ citing three, and $10 \%$ citing all four types of partners ${ }^{7}$.

Two moderating variables are: technological knowledge (proxied by R\&D intensity) and skills-related knowledge (proxied by training intensity) assets. $R \& D$ intensity is measured by the ratio of expenditures on in-house $R \& D$ over sales. Training intensity is measured by the ratio of expenditures on internal and/or external training, specifically for the development of technological innovations, over sales. Each type of knowledge assets is assumed to create firmspecific capabilities that are used to develop new-to-market products, which in turn promote product innovation performance.

Several factors that could have an impact on the sales share of new-to-market products are included as control variables. First, as larger firms with more assets may have a greater ability to undertake innovation activities leading to better innovation performance, the model included the size of the firm measured by the natural logarithm of the number of employees [Firm Size]. Second, recognising that sales outside of Australia could increase the incentive to introduce new-to-market products, we included a $(0,1)$ dummy variable for exports to overseas markets [Export]. Third, a $(0,1)$ dummy variable for whether the firm is part of a larger business [Group] was included to control for the fact that group membership enables a firm to draw on knowledge from their business group, which can increase their capacity to innovate. Fourth, the share of employees with a university degree [Educational Attainment] was included as a control variable because firms with better educated staff could develop more novel products.

\footnotetext{
${ }^{6}$ Of 480 firms in the sample, four reported competitors as the only type of collaborating partner.

${ }^{7}$ Based on the 2006 TIC data (consistent with our 'lagged-variable' Tobit model shown in Table 2).
} 
Fifth, some firms may also invest in process innovation, and given that these firms may need to allocate physical, financial and human assets to the development of both new processes and products, their innovation performance in terms of product sales might not increase (Kohler, Sofka \& Grimpe, 2012). Therefore, following the suggestion of Kohler et al. (2012), we included a $(0,1)$ dummy variable for whether the firm had introduced any new or improved processes for producing or supplying products [Process Innovation] as another control variable. Finally, to control for a complementarity between organisational and technological innovations (Battisti \& Stoneman, 2010), a $(0,1)$ dummy variable for whether the firm implements major changes in corporate strategy, advanced management techniques, or organisational structure with the aim of improving efficiency [Organisational Innovation] was also included ${ }^{8}$.

\subsection{Econometric estimation}

As there are often considerable time lags between investments in innovation activities (incl., collaboration and $\mathrm{R} \& \mathrm{D} /$ training intensities) and the actual innovation performance (the sales share of new-to-market products), we estimate a lagged-variable Tobit model where all independent, moderating and control variables are lagged by one panel wave, that is, by three years. The model is estimated such that the firm's share of sales from new-to-market products observed in the 2010 TIC $(t)$ is regressed on the explanatory variables observed in the 2006 TIC (t-1). Lagged-variable models have been found to have superior predictive validity, especially when innovation performance is measured (Laursen \& Salter, 2006). This approach

\footnotetext{
${ }^{8}$ In a preliminary analysis, we included a series of industry dummy variables (manufacturing; natural resources; infrastructure; retail and wholesale trade; knowledge-intensive business services; and health, education and other services) to reflect different industry conditions; however, no significant industry effects were detected. Therefore, we decided to exclude industry dummies from the final analysis. This exclusion does not alter the statistical significance of the other included variables.
} 
also helps reduce concerns about common method bias since temporal precedence of the predictor variables is firmly established before the outcome is observed (Podsakoff et al. 2003).

Note that although a lagged-variable Tobit model is the main model of this paper, we also perform and report the random-effects (panel) and pooled (cross-sectional) Tobit models to assess the sensitivity and robustness of the results.

\section{Analysis and results}

Table 1 shows the means, standard deviations and correlations for all variables. Table 2 provides estimation results for the Tobit models. To examine moderating effects, we created separate variables for the predictor (IFC), moderators (R\&D intensity and training intensity), and interaction terms (IFC multiplied by R\&D and by training intensity). Both the predictor and moderating variables were mean-centered prior to creating interaction terms to avoid multicollinearity. The significant interaction terms indicate moderating effects. All the Tobit models (lagged-variable, random-effects and pooled) fitted the data at $p<0.001$.

[Insert Table 1]

[Insert Table 2]

As shown in the lagged-variable Tobit model in Table 2, both $\mathrm{R} \& \mathrm{D}(b=2.219)$ and training $(b=2.920)$ intensities had a positive and significant $(p<0.001)$ effect on the share of sales generated by new-to-market products. These results provide evidence for the importance of R\&D and training investments in improving firm innovation performance for new-to-market products. The coefficient for IFC was also significantly positive $(b=1.839, p<0.01)$, indicating the existence of a main positive effect of IFC on the sales share of new-to-market products. 
However, the interaction of R\&D intensity with IFC was negative and significant $(b=-0.385$, $p<0.01$ ), indicating that the benefits of collaboration for innovation performance for new-tomarket products declined at high levels of $R \& D$ intensity compared to low levels of $R \& D$ intensity; thus supporting Hypothesis 1. Similarly, the interaction of training intensity with IFC was also negatively significant $(b=-0.411, p<0.01)$, suggesting that high levels of training intensity reduced the benefits of collaboration for the sales share of new-to-market products compared to low levels of training intensity; thus supporting Hypothesis 2. The signs of the significant coefficients (for both main and interaction effects) remained the same across all three Tobit models. In regard to control variables, organisational innovation was found to be significantly correlated to the sales share of new-to-market products across all models. A significant positive effect of process innovation was observed in the lagged-variable model only, while being part of a larger firm had a negative effect on product innovation performance in the random-effects and pooled models.

Recognising that a good fit model may not necessarily be a good model and thus the best fit model could lead to poor predictions (see Armstrong, 2012; Gigerenzer \& Brighton, 2009), we performed a cross-validation to test for predictive validity of the lagged-variable model in Table 2. Following Woodside's (2013) suggestion, we randomly split the data into two samples: Sample 1 and Sample 2 (each having 240 firms). Each sample was modelled empirically, using Tobit regression. The model from Sample 1 was used to predict the scores (of the sales share of new-to-market products) of Sample 2, and the correlation was computed between predicted scores and actual scores. The process was repeated for Sample 2. Table 3 shows the results. The signs of the coefficients in each Sample remained consistent, and the correlations (Spearman's rho) were moderate and significant. These results suggest that our hypothesised model has acceptable predictive validity. 
To further assess the robustness of the study findings, we estimated several alternative model specifications. First, we replaced an ordinal measure of IFC with a binary measure of whether or not a firm had inter-firm collaboration, and re-estimated all the Tobit models. The estimated results were consistent with the ones using the ordinal measure of IFC. Second, following Armstrong's (2012, p.690) suggestion that "regression-based prediction is most effective when dealing with small numbers of variables", we eliminated all the insignificant control variables and re-estimated the models. The 'reduced model' results were very similar to the 'full-model' results. Third, we replaced IFC with non-inter-firm collaboration (i.e., collaboration with universities or public research institutes) and re-estimated all the models. Since non-inter-firm collaboration involves less appropriation issues (as compared to IFC), it is unlikely that its interaction with $\mathrm{R} \& \mathrm{D}$ and training intensities will produce a lower share of new-to-market product sales. The findings confirmed our expectation, with no significantly negative effects detected ${ }^{9}$. Finally, as the dependent variable for the sales share of new-tomarket products also exhibits overdispersion which occurs as a result of some firms reporting zero shares of new-to-market product sales (see Torugsa \& Arundel, 2013; Wu, 2012), we reanalysed the data using the zero-inflated negative binomial and Poisson models. The signs of the significant coefficients matched our Tobit results. All of these findings reinforce the results of our hypothesis testing.

\section{Discussion}

As expected, both R\&D and training intensities by themselves increase innovation performance in terms of the sales share of new-to-market products. This provides empirical evidence for the importance of technological and skills-related knowledge as the foundation for innovation

\footnotetext{
${ }^{9}$ The moderating effects of the intensity of R\&D and training on the link between non-inter-firm collaboration and product innovation performance, were discussed in our previous article 'Private-public collaboration and innovation performance: Does training matter?', published in 2013 in the International Journal of Innovation Management.
} 
success. Furthermore, that IFC increases innovation performance indicates that collaboration can provide knowledge that help firms gain and exploit innovative opportunities (Laursen \& Salter, 2006). Firms that possess high technological and skills-related knowledge assets may actively engage in IFC with the expectation of gaining benefits from accessing and sharing of non-R\&D/training knowledge assets such as market channels in different geographical locations for their new-to-market products (i.e., accessing opportunities to new markets). However, as hypothesised, in line with TCE and previous research examining the costs of IFC (Buckley \& Casson, 1996; Shrader, 2001), our results show that the association between IFC and innovation performance for new-to-markets is negatively moderated by the intensity of R\&D and training investments that underpin technological and skills-related knowledge assets. In other words, firms with high R\&D and training intensities that collaborated with other firms on innovation have lower sales shares from new-to-market products than collaborating firms with low $R \& D$ and training intensities.

This finding can be explained by the difficulties of managing and controlling the transaction costs (Williamson, 1985) associated with the transfer of technological and skillsrelated knowledge to partner firms. These types of knowledge assets are argued in this study as having high relation specificity for IFC. As suggested by TCE scholars (e.g. Anderson \& Gatigon, 1986; Shrader, 2001), the complex nature of technological and skills-related knowledge (often being tacit and poorly codified) limits the possibility of writing (and enforcing) a formal and comprehensive legal contract that effectively protects the intellectual property and commercial position of each partner firm; while at the same time enabling their shared interest in enhanced innovation performance for new-to-market products through IFC to be achieved. This limitation may expose firms that invest intensively in $R \& D$ and training for innovation performance to the higher risks of opportunism, free-riding, and poaching of highly skilled staff(Belderbos et al., 2004; Dyer, 1997; Stevens, 1996; Williamson, 1985), that 
can follow from having to rely on additional informal and trust-based policing mechanisms in a context where uncertainty and bounded rationality operate. Moreover, risk management for IFC under these conditions can be particularly problematic when the contribution is on the development and/or commercialisation of novel technologies or products, and the necessary skills-related knowledge is likely to be in high demand and short supply in the labour market. In such circumstances, IFC can increase the mobility of skilled staff between partner firms which post-IFC may be in competition (Tether et al., 2005). In this context, IFC could negatively influence a firm's innovation performance for new-to-market products and ability to maximise its sales from new-to-market innovations.

The empirical evidence presented in this study of the main positive effects of $R \& D$ and training intensities on the one hand, and of their negative interaction effects with IFC and the sales share of new-to-market products on the other hand, leads us to propose that investments in developing technological and skills-related knowledge may be more likely to associate positively with an internalisation approach for enhancing innovation performance for new-tomarket products. In other words, the evidence presented here suggests those firms investing intensively in $R \& D$ and innovation-related skills training to enhance their sales of new-tomarket products face high levels of risk and transaction cost in IFC, such that they might be better served by committing the necessary assets to internalise knowledge transfers and pursue innovation in-house.

\section{Conclusions}

Our findings have both theoretical and practical relevance. In respect to theory, the results show that the association between IFC and innovation performance (in the case of new-to-market product development/commercialisation) is moderated by investment for technological and skills-related knowledge assets that have high relation specificity for innovation collaboration 
purposes. As the intensity of investments in these two types of knowledge assets increases, firms find it increasingly difficult to identify and fund the types of essential safeguards that will protect their individual competitive advantage against opportunistic behavior by partner firms which results from unauthorised transfer of proprietary knowledge or skilled staff. If such an outcome occurs, the firm would be unable to maximise its innovation performance and sales from new-to-market products, and so suffer commercially. Consequently, our findings suggest ineffective risk management in IFC involving the transfer of commercially-sensitive, relationspecific technological and skills-related knowledge assets to partner firms (relative to the costs of opting to internalise knowledge transfer) can have the effect of reducing the likelihood of partner firms' innovation performance (for new-to-market products) being enhanced through the IFC. These results provide evidence to support TCE theory relating to the role of transaction costs for relation-specific assets and extend our understanding of the factors that can influence the value of IFC as a pathway to enhanced innovation performance.

In practical terms, this study provides the basis for several managerial insights. In particular, it provides a better understanding of factors relating to the optimal deployment of a firm's knowledge assets, for the purpose of enhancing the firm's innovation performance, which warrant consideration in management decisions regarding engagement in IFC. The main positive association between IFC and the sales share of new-to-market products found in this study should help address concerns by managers about the innovation benefits generated by IFC. However, in deciding to pursue collaboration, managers should not underestimate the potential risks and costs in managing and controlling the knowledge transfer to prevent the loss of an existing competitive advantage derived from its own technological knowledge and skilled staff. In other words, the study findings clearly indicate the need for managers to consider carefully how much their firm has invested in $R \& D$ and training activities and the potential impact of IFC on the level of return on that investment the firm might achieve. 
Whilst this study has raised many important issues, it also has limitations that could be examined in future research. First, in line with TCE we have argued that: firms can invest heavily in $\mathrm{R} \& \mathrm{D}$ and training create firm-specific assets that can be transferred through the process of IFC to collaborating partners that currently lack and are not independently able to create such assets cost-effectively; and that each firm's need to manage the exchange of relation-specific knowledge assets and protect both the singular and collaborative interests of the partner firms will incur high transaction costs. However, data limitations prevented us from directly observing the impact on IFC and innovation performance of the high costs (of risk managing opportunism in conditions characterised by uncertainty, asymmetric flow of information and bounded rationality) that follow from investment in and the exchange of technological and skills-related knowledge assets between partner firms. This limitation suggests an important avenue for future research, namely examining the transaction costs of IFC for innovation and the related knowledge management process.

Second, information on training duration is lacking in the current panel dataset, and the possible bias caused by the use of training expenditure as the only measure of skills-related knowledge should be borne in mind when interpreting our study findings. We suggest that in future research skills-related knowledge, proxied by training intensity, could be measured not only in monetary terms (i.e., training expenditures), but also in non-monetary terms such as training duration (Jones, Kalmiy \& Kauhenen, 2011).

Third, this study assumed that the R\&D/Training-IFC combination has a symmetric relationship with the sales share of new-to-market products. Yet, in reality it is possible that more than one combination of conditions can lead to high/low values in an outcome condition - an asymmetric relationship (see Woodside, 2013). Future research investigating the presence of asymmetries in the relationship between the R\&D/Training-IFC interaction and innovation performance would be of value. Finally, our findings are limited by the self-reported nature of 
the data collection method. Consequently, the subjective and potentially idiosyncratic nature of the respondents' reporting of their firm's collaboration, innovation-related investments and sales generated by new-to-market products, should be borne in mind when interpreting the findings. Further examination of the study theoretical framework to other economies over a longer time period can also help reveal more time- and economy-related effects, thus allowing for greater generalisability of findings.

In summary, we believe this study makes a contribution to the empirical literature on innovation management that has sought to understand the management of knowledge transfer across organisational boundaries. It provides interesting insights into the moderating role of technological and skills-related knowledge assets in the relationship between IFC and the sales share of new-to-market products. Yet, much work remains to be done in identifying, measuring and examining the direct transaction costs related to structural arrangements for managing knowledge transfer and controlling the negative consequences of unwanted leakage of knowledge to partners. Such research would be of great value to scholars and practitioners. We hope our study informs and stimulates further work in this regard. 


\section{References}

Agarwal, S., \& Ramaswami, S.N.(1992). Choice of foreign market entry mode: Impact of ownership, location and internalization factors. Journal of International Business Studies, 23(1), 1-27.

Agmon, T., \& von Glinow, M.(1991). Technology transfer in international business. New York: Oxford University Press.

Ahuja, G.(2000). The duality of collaboration: inducements and opportunities in the formation of interfirm linkages. Strategic Management Journal, 21(3),317-343.

Anderson, E., \& Gatignon, H.(1986). Modes of foreign entry: a transaction propositions. Journal of International Business Studies, 17(3),1-26.

Amstrong, J.C.(2012). Illusions in regression analysis. International Journal of Forecasting, 28(3), 689-694.

Ashton, D., \& Green, F.(1996). Education, training and the global economy. Cheltenham: Edward Elgar.

Battisti, G, \& Stoneman, P.(2010). How innovative are UK firms? evidence from the fourth UK Community Innovation Survey on synergies between technological and organizational innovations. British Journal of Management, 27(1),187-206.

Becker, G.S. 1964. Human Capital: A theoretical and empirical analysis. New York: Columbia University Press.

Belderbos, R., Carree, M., Diederen, B., Lokshin, B., \& Veugelers, R.(2004). Heterogeneity in R\&D cooperation strategies. International Journal of Industrial Organization, 20,1237-1263.

Buckley, P.J., \& Casson, M.C.(1996). An economic model of international joint venture strategy. Journal of International Business Studies, 27(5),849-876.

Cassiman, B., \& Veugelers, R.(2002). R\&D cooperation and spillovers: some empirical evidence from Belgium. American Economic Review, 92(4),1169-1184.

Ciriaci, D.(2011). Intangible resources: the relevance of training for European firms' innovative performance, IPTS working paper on corporate R\&D and innovation No.6/2011. European Union, Luxembourg.

Cohen, W.M., \& Levinthal, D.A.(1990). Absorptive capacity: a new perspective on learning and innovation. Administrative Science Quarterly, 35(1),128-152.

Das, T.K., \& Teng, B.S.(2000). A resource-based theory of strategic alliance. Journal of Management, 26(1),31-61.

Doz, Y.L.(1996). The evaluation of cooperation in strategic alliances: Initial conditions or learning processes. Strategic Management Journal, 17,55-83.

Dyer, H. (1997). Effective interfirm collaboration: How firms minimize transaction costs and maximize transaction value, Strategic Management Journal, 18(7),535-556.

Garud, R., \& Nayyar, P.R.(1994). Transformative capacity continual structuring by intertemporal technology transfer. Strategic Management Journal, 15(5),365-385.

Gigerenzer, G., \& Brighton, H. (2009). Homo heuristicus: Why biased minds make better inferences. Topics in Cognitive Science, 1,107-143.

Jones, D.C., Kalmiy, P., \& Kauhanen, A.(2012). The effects of general and firm-specific training on wages and performance: evidence from banking. Oxford Economic Papers, 64,151-175.

Kohlera, C., W. Sofka, and C. Grimpe. 2012. Selective search, sectoral patterns, and the impact on product innovation performance. Research Policy, 41(8),1344-1356.

Hamel, G.(1991). Competition for competence and inter-partner learning within international strategic alliances. Strategic Management Journal, 12,83-103. 
Harding, R.(2001). Competition and collaboration in German technology transfer. Industrial and Corporate Change, 10(2),389-418.

Laursen, K., \& Salter, A.(2006). Open for innovation: the role of openness in exploring innovation performance among U.K. Manufacturing firms. Strategic Management Journal, 27(2),131-150.

Lhuillery, S., \& Pfister, E.(2009). R\&D cooperation and failures in innovation projects: Empirical evidence from French CIS data. Research Policy, 38(1),45-57.

Lundvall, B.A., \& Nielsen, P.(2007). Knowledge management and innovation performance. International Journal of Manpower, 28,207-223.

Mansfield, E., \& Lee, J.Y.(1996). The modern university: contributor to industrial innovation and recipient of industrial R\&D support. Research Policy, 25(7),1047-1058.

Mention, A.L.(2011). Co-operation and co-opetition as open innovation practices in the service sector: Which influence on innovation novelty?. Technovation, 31,44-53.

Mitchell, W., \& Singh, K.(1996). Survival of businesses using collaborative relationships to commercialize complex goods. Strategic Management Journal, 7,169-195.

Mora-Valentin, E.M., Montoro-Sanchez, A., \& Guerras-Martin L.A.(2004). Determining factors in the success of R\&D cooperative agreements between firms and research organizations. Research Policy, 33(1),17-40.

Mowery, D.C., Oxley, J.E., \& Silverman, B.S.(1998). Technological overlap and interfirm cooperation implications for the resource-based view of the firm. Research Policy, 27(5),507-523.

Nonaka, I.(1994).A dynamic theory of organizational knowledge creation. Organization Science,5(1),14-37.

Nonaka, I., Toyama, R., \& Nagata, A.(2000). A firm as a knowledge-creating entity: A new perspective on the theory of the firm. Industrial and Corporate Change, 9(1),1-20.

Nooteboom, B.(1993). An analysis of specificity in transaction cost economics. Organization Studies, 14(3),443-451.

OECD/Eurostat (1997). OECD Oslo manual, $2^{\text {rd }}$ ed. Paris: OECD Publishing.

OECD/Eurostat (2005). OECD Oslo manual, $3^{\text {rd }}$ ed. Paris: OECD Publishing.

Oxley, J.E., \& Sampson, R.C.(2004). The scope and governance of international R\&D alliances. Strategic Management Journal, 25,723-749.

Pisano, G.P. (1990). The R\&D boundaries of the firm: An empirical analysis. Administrative Science Quarterly, 35(1),153-176.

Piva, M., \& Vivarelli, M.(2009). The role of skills as a major driver of corporate R\&D. International Journal of Manpower, 30,835-852.

Podsakoff, P.M., MacKenzie, S.M. \& Podsakoff, N.P.(2003). Common method variance in behavioral research: A critical review of the literature and recommended remedies. Journal of Applied Psychology, 88(5),879-903.

Powell, W.W., Koput, K.W., \& Smith-Doerr, L.(1996). Interorganizational collaboration and the locus of innovation: Networks of learning in biotechnology. Administrative Science Quarterly, 41(1),116-145.

Prais, S.J.(1995). Productivity, education and training. Cambridge: CUP.

Seth, A., \& Thomas, H. (1994). Theories of the firm: Implications for strategy research. Journal of Management Studies, 31(2),165-191.

Shrader, R.C.(2001). Collaboration and performance in foreign markets: The case of young high technology manufacturing firms. Academy of Management Journal, 44(1), 45-60.

Simon, H.(1991). Bounded rationality and organizational learning. Organization Science, 2(1), 125-134. 
Stevens, M.(1996). Transferable training and poaching externalities. In A.L. Booth \& D.J. Snow (Eds.). Acquiring skills: Market failures, their symptoms and policy responses: 19-40. Cambridge, UK: Cambridge University Press.

Svetlic, I., \& Stavrou-Costea, E.(2007). Connecting human resources management and knowledge management. International Journal of Manpower, 28,197-206.

Teece, D.J.(1992). Competition, cooperation, and innovation: Organizational arrangements for regimes of rapid technological progress. Journal of Economic Behavior \& Organization, 18(1),1-25.

Tether, B., Mina, A., Consoli, D., \& Gagliardi, D.(2005). A literature review on skills and innovation: How does successful innovation impact on the demand for skills and how do skills drive innovation?. A CRIC Report for the Department of Trade and Industry. ESRC Centre for Research on Innovation and Competition, Manchester: University of Manchester.

Toner, P.(2011). Workforce skills and innovation: An overview of major themes in the literature. OECD Directorate for Sciences, Technology and Industry (SIT), Centre for Education and Innovation (CERI), Paris: OECD publishing.

Torugsa, N., \& Arundel, A.(2013). Private-public collaboration and innovation performance: Does training matter?. International Journal of Innovation Management, 17(3),1-20.

Tsai, K.H., \& Hsieh, M.H.(2009). How different types of partners influence innovative product sales: Does technological capacity matter?. Journal of Business Research, 62,1321-1328.

von Hippel, E.(1988). The sources of innovation, Oxford: Oxford University Press.

Williamson, O.E.(1985). The economic institutions of capitalism. New York: Free Press.

Williamson, O.E.(2002). The theory of the firm as governance structure: From choice to contract. Economic Perspective, 16(3),171-196.

Woodside, A. (2013). Moving beyond multiple regression analysis to algorithms: Calling for adoption of a paradigm shift from symmetric to asymmetric thinking in data analysis and crafting theory. Journal of Business Research, 66(4), 463-472.

$\mathrm{Wu}, \mathrm{J} .(2012)$. Technological collaboration in product innovation: The role of market competition and sectoral technological intensity. Research Policy, 41(2),489-496.

Zeng, S.X., Xie, X.M., \& Tam, C.M.(2010). Relationship between cooperation networks and innovation performance of SMEs. Technovation, 30,181-194. 
Table 1: Means, standard deviations and correlations

\begin{tabular}{|c|c|c|c|c|c|c|c|c|c|c|}
\hline Variable & 1 & 2 & 3 & 4 & 5 & 6 & 7 & 8 & 9 & 10 \\
\hline \multicolumn{11}{|c|}{ 1. Sales share of new-to-market products $t$} \\
\hline 2. $\mathrm{IFC}_{t-1}$ & $0.123^{* *}$ & & & & & & & & & \\
\hline 3.R\&D intensity $t_{t-1}$ & $0.169^{* * *}$ & $0.201 * * *$ & & & & & & & & \\
\hline 4.Training intensity $t_{t-1}$ & $0.133^{* * *}$ & $0.123^{* *}$ & $0.297 * * *$ & & & & & & & \\
\hline 5.Firm size $e_{t-1}$ & -0.036 & 0.045 & 0.011 & $-0.123^{* *}$ & & & & & & \\
\hline 6. Export $t_{t-1}$ & 0.046 & $0.090^{*}$ & $0.222 * * *$ & -0.052 & $0.180^{* * *}$ & & & & & \\
\hline 7. Group $t-1$ & 0.015 & -0.036 & -0.011 & $-0.098^{*}$ & $0.208^{* * *}$ & 0.067 & & & & \\
\hline 8.Educational attainment $t_{t-1}$ & 0.060 & $0.126^{* *}$ & $0.159^{* * *}$ & $0.218^{* * *}$ & -0.055 & $0.167^{* * *}$ & -0.030 & & & \\
\hline 9.Process innovation ${ }_{t-1}$ & $0.138^{* * *}$ & $0.102 *$ & 0.031 & 0.044 & $0.141^{* * *}$ & 0.042 & 0.052 & 0.079 & & \\
\hline 10. Organistional innovation ${ }_{t-1}$ & $0.136^{* * *}$ & $0.178^{* * *}$ & $0.099 *$ & 0.039 & $0.110^{*}$ & 0.056 & 0.081 & $0.151^{* *}$ & $0.098^{*}$ & \\
\hline Mean & 8.028 & 1.170 & 2.345 & 0.678 & 2.928 & 0.240 & 0.330 & 17.079 & 0.690 & 0.650 \\
\hline Standard deviation & 16.828 & 1.470 & 7.216 & 1.688 & 1.039 & 0.426 & 0.470 & 26.049 & 0.461 & 0.476 \\
\hline
\end{tabular}


Table 2: Tobit results for the sales share of new-to-market products

Tobit Model

Dependent Variable: The Sales Share of New-to-Market Products

\begin{tabular}{|c|c|c|c|}
\hline & & & \\
\hline & Lagged-variable & Random-effects & Pooled \\
\hline Constant & $-16.631(5.614)^{* * *}$ & $-20.582(4.274)^{* * *}$ & $-20.562(4.147)^{* * *}$ \\
\hline Firm size & $-2.353(1.580)$ & $0.745(1.139)$ & $0.652(1.093)$ \\
\hline Export & $-0.394(3.640)$ & $0.896(2.653)$ & $1.040(2.582)$ \\
\hline Group & $3.887(3.307)$ & $-4.448(2.326)^{*}$ & $-4.183(2.267)^{*}$ \\
\hline Educational attainment & $-0.104(0.058)$ & $0.071(0.042)$ & $0.065(0.040)$ \\
\hline Process innovation & $6.600(3.412)^{* *}$ & $1.337(2.553)$ & $1.413(2.531)$ \\
\hline Organisational innovation & $7.562(3.353)^{* * *}$ & $7.373(2.529)^{* * *}$ & $7.610(2.516)^{* * *}$ \\
\hline IFC & $1.839(1.051)^{* *}$ & $1.701(0.732)^{* *}$ & $1.686(0.726)^{* *}$ \\
\hline R\&D intensity & $2.219(0.324)^{* * *}$ & $1.925(0.174)^{* * *}$ & $1.988(0.170)^{* * *}$ \\
\hline Training intensity & $2.920(1.309)^{* * *}$ & $1.499(0.787)^{*}$ & $1.550(0.782)^{* *}$ \\
\hline $\mathrm{R} \& \mathrm{D}$ intensity $\times \mathrm{IFC}$ & $-0.385(0.164)^{* *}$ & $-0.328(0.092)^{*}$ & $-0.348(0.171)^{*}$ \\
\hline Training intensity $\times$ IFC & $-0.411(0.748)^{* *}$ & $-0.342(0.478)^{*}$ & $-0.294(0.476)^{*}$ \\
\hline Number of observations & 480 & $960^{\mathrm{a}}$ & 960 \\
\hline Log-likelihood & -1092.619 & -1992.789 & -1994.778 \\
\hline $\operatorname{LR} X^{2}(d f)$ & $81.48(11)^{* * *}$ & $76.97(11)^{* * *}$ & $87.48(11)^{* * *}$ \\
\hline Left-censored observations & 279 & 600 & 600 \\
\hline Right-censored observations & 4 & 4 & 4 \\
\hline
\end{tabular}

${ }^{*} p<0.05,{ }^{* *} p<0.01,{ }^{* * *} p<0.001$. Standard errors are in parentheses. ${ }^{a} 2$ observations per group. 
Table 3: Cross-validation test

Dependent Variable (DV): The Sales Share of New-to-Market Productst

\begin{tabular}{|c|c|c|c|}
\hline \multicolumn{2}{|l|}{ Sample $1(n=240)$} & \multicolumn{2}{|l|}{ Sample $2(n=240)$} \\
\hline Constant & $-18.249(7.914)^{* * *}$ & Constant & $-14.298(7.975)^{*}$ \\
\hline Control variables & (included) & Control variables & (included) \\
\hline $\mathrm{IFC}_{t-1}$ & $1.625(1.537)^{*}$ & $\mathrm{IFC}_{t-1}$ & $1.599(1.397)^{*}$ \\
\hline R\&D intensity $y_{t-1}$ & $2.099(0.396)^{* * *}$ & $R \& D$ intensity $t_{t-1}$ & $2.839(0.641)^{* * *}$ \\
\hline Training intensity $t_{t-1}$ & $3.431(0.413)^{* * *}$ & Training intensity ${ }_{t-1}$ & $1.610(0.275)^{*}$ \\
\hline R\&D intensity ${ }_{t-1} \times \mathrm{IFC}_{t-1}$ & $-0.896(0.209)^{* *}$ & $\mathrm{R} \& \mathrm{D}$ intensity ${ }_{t-1} \times \mathrm{IFC}_{t-1}$ & $-0.629(0.293)^{*}$ \\
\hline Training intensity $t_{t-1} \times \mathrm{IFC}_{t-1}$ & $-0.817(0.779)^{* *}$ & Training intensity $y_{t-1} \times \mathrm{IFC}_{t-1}$ & $-0.692(0.672)^{*}$ \\
\hline Log-likelihood & -520.488 & Log-likelihood & -518.352 \\
\hline $\operatorname{LR} X^{2}(d f)$ & $39.95(5)^{* * *}$ & $\operatorname{LR} X^{2}(d f)$ & $37.98(5)^{* * *}$ \\
\hline \multicolumn{2}{|c|}{ Spearman DV and pre1 if Sample $=2$} & \multicolumn{2}{|c|}{ Spearman DV and pre2 if Sample $=1$} \\
\hline \multicolumn{2}{|l|}{ Spearman's rho $=0.5042$} & \multicolumn{2}{|l|}{ Spearman's rho $=0.5455$} \\
\hline \multicolumn{2}{|c|}{$\begin{array}{l}\text { Test of Ho: DV and pre } 1 \text { are independent Prob }>[t]= \\
0.000\end{array}$} & \multicolumn{2}{|c|}{$\begin{array}{l}\text { Test of Ho: DV and pre } 2 \text { are independent Prob }>[t]= \\
0.000\end{array}$} \\
\hline
\end{tabular}

